ESTUDIOS $\lambda$ AMBDA.

Teoría y práctica de la didáctica

en lengua y literatura

\title{
Otras transformaciones de un género imperialista
}

(Other Transformations of an Imperialist Genre)

Francisco González Gaxiola ${ }^{\oplus}$, Universidad de Sonora, Sonora, México

\section{Volumen 3, número 1}

Septiembre de 2018

p. 6-19

Este número se publicó el 17 de septiembre de 2018

ISSN: 2448-5942, doi: https://doi.org/10.36799/el.v3i1.70

\section{RECENSIÓN}

Citar este artículo como:

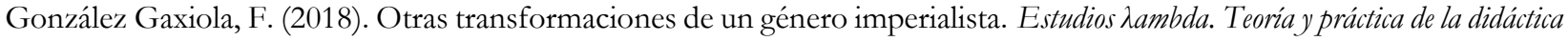
en lengua y literatura. , 3(1), 6-19. https://doi.org/10.36799/el.v3i1.70

Derechos de autor: El autor o autores conservan en todo momento sus derechos morales y patrimoniales sobre la obra; la obra no se puede alterar, transformar o ampliar; siempre debe reconocerse la autoría del documento referido. Ninguna de las modalidades de los documentos publicados en Estudios $\lambda a m b d a$. Teoría y práctica de la didáctica en lengua y literatura tienen fines comerciales de naturaleza alguna.

Los contenidos de este artículo están bajo una licencia de Creative Commons Atribución No Comercial- Sin Derivadas 4.0 Internacional @) (1) $\Theta$ 


\title{
Otras transformaciones de un género imperialista
}

\author{
(Other Transformations of an Imperialist Genre)
}

\author{
FRANCISCO GONZÁLEZ GAXIOLA ${ }^{1}$
}

\section{RESUMEN}

"Formas alternativas del género narrativo" que aquí se comenta, es producto de un proyecto interdisciplinar con tres direcciones identificadas y complementadas en la búsqueda de géneros diferentes al narrativo tradicional verbal (oral o impreso). Para textos con esas modalidades tenemos diversas direcciones: a) el marco teórico: hermenéutico sociohistórico, b) la reflexión teóricodidáctica de en las revistas ilustradas con imagen fija y en movimiento (film), y c) el jurídico narrativo mediante el análisis de los testimonios en la corte. Cada una de estas líneas de generación y aplicación del conocimiento está dirigida por un miembro titular y uno o dos colaboradores, además de los estudiantes que trabajan las líneas de sus respectivos tutores. "Formas alternativas del género narrativo" se propone identificar, aunque no de manera exhaustiva, géneros y formatos diferentes al tradicionalmente conocido como relato literario, breve o extenso y que, como término sombrilla, podría denominarse en su forma escrita, épica. En este género cabrían subgéneros como el cuento con múltiples tipos y subtipos, fábulas, leyendas, novelas, mitos, entre otros. Todos ellos en formato impreso, es decir, producido para su difusión masiva, en imprenta a partir de la aportación de Gutenberg. Tenemos que aclarar que, en lo referente a soporte mediático, antiguamente existieron esos mismos géneros escritos (incluso en su forma oral antes de la escritura), pero fueron textos escritos a mano, en pergamino, en piedra, en tejas, en papel y otros medios y formatos materiales.

PALABRAS CLAVE: forma y género literario, cómic, cine, identidad cultural, literatura popular, ilustraciones

\begin{abstract}
"Alternative forms of the narrative genre" that is commented here, is the product of an interdisciplinary project with three directions identified and complemented in the search of genres different from the traditional verbal narrative (oral or printed). For texts with these modalities we have different directions: a) the theoretical framework: socio-historical hermeneutic, b) the theoretical-didactic reflection of the illustrated magazines with fixed and moving image (film), and c) the narrative legal through the analysis of the Term in the court. A member and one or two collaborators, in addition to the students who work the lines of their respective tutors, direct each of these lines of generation and application of knowledge. "Alternative forms of the narrative genre" aims to identify, although not exhaustively, genres and formats different from the traditionally known literary story, brief or extensive and which, as an umbrella term, could be called in its written form, epic. In this genre would fit subgenres such as the story with multiple types and subtypes, fables, legends, novels, myths, among others. All of them in printed format, that is, produced for mass dissemination, in print from the contribution of Gutenberg. We must clarify that, in terms of media support, formerly there were those same genres written (even in its oral form before writing), but were written by hand, on parchment, in stone, on tiles, on paper and other media and material formats.
\end{abstract}

KEYWORDS: Literary Forms and Genres, comics, films, cultural identity, popular literature, illustrations

\footnotetext{
${ }^{1}$ Profesor investigador del Departamento de Letras y Lingüística de la Universidad de Sonora. francisco.gonzalez@unison.mx. Maestría y Doctorado en Lengua y Literatura Españolas por el Departamento de Lenguas Clásicas y Romances, Michigan State University. Posdoctorado en Didáctica de la Lengua y la Literatura en la Universidad de Barcelona (2003). Profesor de Didáctica de la lengua y la literatura, y Teoría literaria en la Universidad de Sonora. Proyectos de investigación: "Las teorías literarias y su aplicación en la enseñanza de la literatura". "La influencia de las nuevas tecnologías en la Didáctica de lengua y literatura".
}

González Gaxiola doi: https://doi.org/10.36799/el.v3i1.70 Volumen 3, número 1, Año 2018, ISSN: 2448-5942 
"Formas alternativas del género narrativo" que aquí presentamos, es producto de un proyecto interdisciplinar con tres direcciones identificadas y complementadas en la búsqueda de géneros diferentes al narrativo tradicional verbal (oral o impreso). Para textos con esas modalidades tenemos diversas direcciones: a) el marco teórico: hermenéutico socio histórico, b) la reflexión teórico-didáctica de en las revistas ilustradas con imagen fija y en movimiento (film), y c) el jurídico narrativo mediante el análisis de los testimonios en la corte. Cada una de estas líneas de generación y aplicación del conocimiento está dirigida por un miembro titular y uno o dos colaboradores, además de los estudiantes que trabajan las líneas de sus respectivos tutores.

"Formas alternativas del género narrativo" se propone identificar, aunque no de manera exhaustiva, géneros y formatos diferentes al tradicionalmente conocido como relato literario, breve o extenso y que, como término sombrilla, podría denominarse en su forma escrita, épica. En este género cabrían subgéneros como el cuento con múltiples tipos y subtipos, fábulas, leyendas, novelas, mitos, entre otros. Todos ellos en formato impreso, es decir, producido para su difusión masiva, en imprenta a partir de la aportación de Gutenberg. Tenemos que aclarar que, en lo referente a soporte mediático, antiguamente existieron esos mismos géneros escritos (incluso en su forma oral antes de la escritura), pero fueron textos escritos a mano, en pergamino, en piedra, en tejas, en papel y otros medios y formatos materiales.

Hemos tratado de llamar la atención a una variante no desconocida, de hecho muy popular, se trata de relatos contados vía testimonial o ilustrados vía impresa o en medio fílmico. La variante a la que ponemos énfasis se refiere a las revistas ilustradas, también conocidas con nombres como comics, cartoons, manga, caricaturas, novela gráfica, novela visual y, cuando son animadas, ánime. La curiosidad por este formato, también impreso y de producción y consumo masivo, se debió a la intromisión reciente y repentina de esta modalidad con que se adueñaron de las aulas de educación primaria en Europa y los Estados Unidos de América. A dicho género, se le vislumbró primero como posibilidad, luego se le rechazó, incluso se le satanizó, y por fin terminó aceptándose o por ser más atractivo y prometedor el acercamiento que el rechazo. Terminó imponiéndose la novedad. Se ha de haber formulado la pregunta de por qué no recurrir a los comics para enseñar tantas cosas en las diversas disciplinas, no sólo por su argumento de ficción, sino además por la forma mimética de la literatura seria, pero también con variante infantil. Tendríamos entonces la pregunta nuevamente 
formulada ¿por qué no utilizar las ilustraciones para representar las grandes obras de la literatura universal?, o ¿por qué no enseñar las ciencias naturales, física, astronomía, química, a través de personajes de ficción del tamaño que se le requiera, con tal de que el contenido con contornos seduzca a los alumnos no sólo de primaria, también de secundaria, preparatoria inclusive?

El género narrativo se divide en literario y no literario. El género narrativo no literario es antiquísimo; se concreta en relatos en los que los adultos transmiten a la nueva generación sus saberes y en ellos se comunica la experiencia de manera didáctica, pero sobre todo porque los relatos, comunes a todas las culturas y tiempos, constituyen una estrategia para apresar la realidad, de comprender el mundo, la existencia y la identidad, la procedencia, la finalidad y el sentido de la vida. Sus variantes constituyen un gran número: mitos, rumores, chismes, reportes y reportajes, avisos, noticias, memoranda, minutas o actas, cartas, noticieros. El epítome, ejemplo emblemático de este apartado, es el género narrativo histórico.

Por otro lado, el género narrativo literario es igualmente extenso dado que cualquier género no narrativo puede pasar a literario mediante varios procedimientos, aunque quizá el más elemental sea el de hacerlo aparecer inserto en algún otro género denominado literario; por ejemplo, una conversación real o figurada, cuando aparece inserta en una novela, pasa a ser literario. Cualquier otro género cuya finalidad primaria sea comunicar puede elevar su estatus cuando se le reconsidere en su construcción y recepción, es decir, que sea modificada retóricamente de tal modo que agrade o busque agradar a un oyente, a una audiencia, a un lector o usuario. Con el hecho de que esté bien escrita (con todo lo subjetivo que pueda parecer la frase "bien escrita"), calificada por una autoridad académica o social que así lo califique, será suficiente. Un par de ejemplos bastarán: los escritos de memorias de guerra de Winston Churchill o las disquisiciones filosóficas de Bertrand Russell, fueron a tal grado reconocidas que incluso llegaron a ganar el premio Nobel de literatura, no así los escritos económico filosóficos de Carlos Marx ni los de Vladimir Lenin, tampoco los de Hegel, tan influyentes en el desarrollo del pensamiento humano. Es posible, como se afirma antes, que tales textos pudieran ser denominados literatura con que se les asignara un equis valor agregado de tipo artístico aunque no necesariamente ideológico. 
Los géneros narrativos tradicionales desde los tiempos antiguos, repetimos, son el relato folklórico, el cuento, la fábula, la leyenda y el mito, más la compleja y problemática novela. Los supergéneros reconocidos desde la antigüedad clásica, la épica, la tragedia y la lírica, dieron origen con el tiempo a muchísimos subgéneros. De la primera surgieron algunos extensos y sublimes como la epopeya, de la cual según Lukacs, proviene la novela (afirmación controversial, sin embargo); segundo, la tragedia, un tipo de drama radical, género originalmente en verso y a la cual le dedicó Aristóteles un tratado claro y profundo, y cuya estructura allí presentada ha sido utilizada como base o guía para los relatos del género narrativo también; y tercero, la lírica, el género de las emociones, que derivó en géneros producidos tanto por gente noble o de la corte, culta y con suficiente tiempo disponible pero también tenemos la lírica popular. De la lírica hay una versión popular sobre el manejo de los sentimientos y las emociones inmemorial, e incluso hay poemas de temática mixta entre sentimental y narrativo como el romance español o nuestros corridos mexicanos

El paraíso clasificatorio de los géneros y subgéneros, en el cual toda modalidad literaria cabía en su respectivo nicho, era fijo y estuvo vigente durante mucho tiempo pero se rompió sin embargo poco a poco debido principalmente a la innovación de géneros que no cabían propiamente en las tipologías conocidas. Razones hay algunas pero quizá la más detonante fue la que introdujo variantes de textos con base inestable, la propuesta de Raymundo Lull, el libro clásico chino de la adivinación, el I Ching, o también Vida y opiniones del caballero Tristran Shandy que burlaba la ficción saliéndose de ella, o su correspondiente francesa, Jacques el fatalista de Denis Diderot. Estos, los más representativos, fueron superados con mucho en el siglo XX por el taller de literatura potencial, mejor conocido como OULIPO dirigido por Raymond Queneau y Francois le Lionnais con su obra 10 mil millares de sonetos. Estos últimos no narrativos ciertamente, pero sí literarios y en cierta manera con una capa de ironía. La lista se puede extender, pero estos casos son trascendentes porque siendo textos de base impresa en papel, sin novedad aparente alguna en su soporte material, trastocaban el orden hasta entonces conocido y no permitían una ubicación segura en las taxonomías literarias, o al menos se les reconocía con renuencia, como excepciones y con dejos de incomodidad para los clasificadores y categorizadores.

En vista de la situación vigente nos dimos a la tarea de buscar los géneros literarios que no fueran los tradicionales, es decir, los plenamente reconocidos como tales: cuento, fábula, leyenda, mito, 
novela, incluso la poesía cuando es narrativa como Venus y Adonis de Shakespeare o incluso textos más extensos como la novela en verso Eugenio Onneguin del ruso Alexandre Pushkin, Además se da el caso curioso del teatro y del cine que correspondiendo a la mimesis - no a la diégesis- es decir que se centran en el mostrar no en el relatar con palabras, de cualquier manera exhiben una historia, que a su vez se puede traducir a relato.

Los géneros tradicionalmente narrativos fueron reconocidos como tales en forma impresa $\mathrm{O}$ escrita. Textos muy antiguos como los libros de la Biblia no adquirieron su forma fija sino hasta que se les dio forma escrita, o más antiguamente hacia 1776 a.C. el Código de Hammurabi, fue fijado porque se pudo leer en letras sobre un material. Antes de la escritura (aparecida aproximadamente hacia 3000 años a.C.) las manifestaciones que ahora denominamos literarias eran más bien de naturaleza histórica o antropológica: cantos en ceremonias de iniciación o ritos de paso, mantras, oraciones, rezos ceremoniales, rituales de tipo funerario, por ejemplo, así como las producciones que todavía realizan las sociedades ágrafas, las de tantas etnias distribuidas en el mundo y de las cuales México tiene un amplio número. Y Sonora con cerca de ocho o nueve etnias, ha elevado el estatus de las producciones autóctonas desde la curiosa mirada antropológica hasta un carácter literario o cuasi literario, generalmente narrativo.

Las tecnologías de la información y comunicación (TICs) que siempre son nuevas y continuamente se están renovando, han incursionado de un tiempo a otro en la gestación de nuevos y múltiples tipos híbridos, aunque en un principio la innovación se limitara a la traslación de formato impreso a un formato digital, sin ninguna otra modificación. Lo que favoreció en rapidez y eficacia la computadora fue la hipertextualidad como forma no lineal de escribir y de leer. Esto, sin embargo, la literatura escrita ya lo venía haciendo sin haberle dado tanta importancia ni trascendencia. Recursos utilizados por la hipertextualidad son estrategias de presentación secundaria de información como las notas de pie de página, las referencias cruzadas, los epígrafes, las citas textuales, entre otros tantos, sin embargo, la denominada hipetextualidad se elevó exponencialmente con la posibilidad de multiplicar los caminos de lectura, de monolineal a multilineal.

De cualquier manera, las TICs introdujeron la multimedia con imagen fija o en movimiento, sonido, profundidad, entonces los géneros narrativos (aunque no exclusivamente) adquirieron nuevas 
dimensiones antes circunscritas a la ópera, al teatro, al cine. El desarrollo de las variantes narrativas no termina allí pues se vuelve más compleja. La multilinealidad ha favorecido la diversidad de estructuras narrativas simultáneas, la interacción del usuario o lector, los soportes materiales, la posibilidad de que el usuario intervenga para modificar el argumento de una historia. Iniciados estos procedimientos en los videojuegos y en los juegos de rotación de rol, estos se han llevado a la literatura seria, al formato digital desde las primeras producciones electrónicas e hipertextuales de principios de los noventa del siglo XX: Afternoon a Story (1990) de Michael Joyce, Victory Garden (1992) de Stuart Moulthrop, Patchwork Girl (1995) de Shelley Jackson como experimentos de géneros cruzados.

Siguiendo esta pista podemos entrar en una carrera desaforada que nos producirá vértigo por lo atropellado y prometedor de la empresa. Pero es un hecho que los estudios filológicos tienen mucho material que observar, analizar, interpretar y valorar mediante el recurso a nuevas variables para enfrentar todo un universo de virtualidades que poco a poco se van convirtiendo en realidad.

No nos centraremos en los nuevos productos llegados al mercado, que los hay y muchos. No estableceremos relaciones, correspondencias, comparaciones entre lo tradicional y lo innovador. Nos detendremos, como lo afirmamos al principio, en las historietas ilustradas con o sin finalidad didáctica, las historietas que cuentan un relato mediante una sucesión de viñetas o paneles en formato libreta o libro impreso. Cuando la ilustración, el dibujo o la viñeta adquieren movimiento lo convertimos al formato fílmico en ánime por ejemplo, o cuando es realista es el film narrativo. Y por fin tenemos los testimonios narrativos utilizados en el ámbito jurídico como versiones narrativas periciales. El interés por este tipo de producto cultural y de mercado en sí ostenta un alto interés, comenzando por responder a la pregunta, por qué se mantiene su popularidad y consumo a pesar de lo inmensamente atractivos que son los entretenimientos ofrecidos por la computadora. En Europa, Los Estados Unidos de América, Japón, Corea del Sur, incluso América Latina constituyen un fenómeno cultural, económico, ideológico, político, histórico, social, psicológico.

Consideramos que nuestro primer acercamiento al mundo de las formas alternativas del género narrativo está justificado en cuanto hemos tratado de acercárnosle desde diferentes perspectivas, sobre todo el punto de vista que añade al texto imágenes o dibujos para, secuenciados, formar una historia. En el caso de las historietas ilustradas o comics existen abundantes estudios sobre 
crítica de comics, no tanto sobre teoría, en términos relativos, por supuesto. En el campo al que nos enfrentamos, el de las humanidades y el de la lengua y la literatura, los comics merecen ser estudiados ampliamente, seriamente desde la academia de la crítica literaria, y ser igualmente abordados tanto desde la teoría como desde la práctica de la didáctica de la lengua y la literatura. Estamos enterados que las propuestas tímidas y discretas por acercar los comics a la escuela pueden ser calificadas como atrevimientos descabellados, iconoclastas, perversos, incluso como carentes de seriedad. Sin embargo, la visión que se tiene de los éxitos en otras latitudes y lo prometedor para tratar problemas no necesariamente desde la perspectiva de la didáctica de la lengua y la literatura sino de tipo psicológico como actitudinales, comportamentales, de léxico, de desarrollo de la imaginación, y todo esto desde una perspectiva lúdica, se convierte en un tema digno de estudio académico universitario.

Nos acercamos a esta investigación desde una perspectiva tanto teórica como práctica pero la enriquecemos con complementos disciplinarios de lo específicamente literario, la literariedad. Nuestro acercamiento metodológico cuantitativo no pudimos hacerlo surgir a partir de la selección de un corpus considerablemente comprehensivo, pues la parte del universo seleccionada hubiera sido demasiado poco representativa dada la cantidad exorbitante de categorías y géneros narrativos que seleccionar. En virtud de esta razón expuesta, opuesta a como nos la imaginábamos en un principio, nos hizo concentramos en los géneros conocidos como historietas. Aun así, si redujéramos la más significativa de las aportaciones, la centrada en un solo sub-género, las historietas ilustradas como representante emblemático, es decir, en una relación género especie, la empresa se manifestaría gigante pues ella seguiría apareciendo altamente variada sobre todo en su presentación seria de temática adulta. Por lo contrario, en lugar de buscar normas generales y estables en una perspectiva nomotética, nos hemos servido de casos concretos, dirigida nuestra aproximación a lo ideográfico. Los diez investigadores (seis profesores y cuatro estudiantes de posgrado que incorporamos por sus aportaciones disciplinares) se alinean temáticamente de la manera como a continuación se muestra:

\section{Contextos}

1. Hermenéutica y sociedad

2. Perspectiva lingüístico-filosófica

González Gaxiola doi: https://doi.org/10.36799/el.v3i1.70 Volumen 3, número 1, Año 2018, ISSN: 2448-5942 


\section{Cómics y novela gráfica}

3. Marco contextual de la narrativa gráfica

4. Novela gráfica sin textos.

5. Una etapa en la narrativa interactiva

\section{El cine narrativo}

6. El cine en modalidades

7. El cine en el aula

8. Cómics en movimiento

\section{Narrativa lingüística-forense}

9. Testimonios periciales

El campo teórico de Patricia Guerrero de la Llata es el análisis hermenéutico de productos culturales. Esta área del conocimiento utiliza la interdisciplina para el estudio de las formas, las prácticas y las instituciones que producen y difunden significados en una sociedad. Estudia sobre todo los discursos reguladores de prácticas sociales y el papel de los juegos de poder en las actividades cotidianas que dan sentido a la realidad social y remiten a cuestiones de ideología, de nacionalidad, de etnia, de género, de clase social. Analiza significados y valores implicados en las prácticas cotidianas que se producen y se difunden entre los distintos grupos sociales. Su principal objetivo es definir el estudio de la cultura como un terreno de análisis conceptualmente pertinente y teóricamente fundamentado.

En "Habibi: Dialéctica cultura-subjetividad en la construcción de las identidades” de Patricia Guerrero de la Llata y María Edith Araoz Robles, se analiza el proceso de representación de lo femenino en las gráficas de la novela, así como la conformación y asimilación de los roles de género que se muestran implícita o explícitamente en los actos, los dichos y las decisiones tomadas tanto por la protagonista, como las que toman por ella otros personajes. Asimismo, se ubica el análisis de la construcción del sujeto femenino en el ámbito de la cultura representada. Se llega a la conclusión de que en el proceso de construcción de identidades se puede observar cómo la construcción subjetiva vinculada con concepciones simbólicas de poder permite la movilidad ante la interseccionalidad. 
Francisco Félix Martínez y Francisco González Gaxiola nos introducen a la filosofía de la metonimia en cuanto que parte del supuesto de que toda representación de la realidad está en principio basado en la metonimia y en el caso de las viñetas ocurre con mayor razón. Su estudio originado en la historia de los cómics avanza a la problematización de las imágenes encuadradas como dibujos los que al igual que las fotografías siempre recuperan una parte del todo inabarcable. Félix Martínez revisa en "En busca de la teoría de la metonimia: Hacia una hermenéutica analógica" cómo desde la antigüedad, la metonimia ha sido un tropo menospreciado por los estudios del lenguaje. Ya en la modernidad, Paul Ricoeur desarrolló una teoría de la metáfora que tenía como característica fundamental la proyección y exponenciación del sentido mediante este tropo, desestimando completamente la metonimia en su planteamiento filosófico por ser un mecanismo retórico de la semiótica y no de la semántica. Sin embargo, ya en el siglo XX, la lingüística cognitiva, como en los trabajos de Antonio Barcelona, y la semiótica, como en las propuestas de Eliseo Verón, encuentran en la metonimia un recurso trascendental de sus hipótesis. Así mismo, ya en el siglo XXI, en los trabajos de Hermenéutica Analógica, de mano de Mauricio Beuchot, la metonimia articula los caminos de la interpretación entre la equivocidad y la univocidad. Por lo que en las siguientes páginas se revisará, desde tres perspectivas (la lingüística cognitiva, la semiósis social y la hermenéutica analógica), los aportes de sentido que puede brindar la metonimia.

Cristian Eduardo Elizalde Velásquez y Patricia Guerrero de la Llata aportan "Del cómic a la novela gráfica: Un acercamiento a los orígenes”, en el que realiza un breve recorrido histórico, en donde se argumenta y se confrontan las principales tendencias, asimismo, se hace un especial énfasis en las definiciones que algunos de los teóricos o historietistas han aportado al medio a lo largo del tiempo: los elementos que componen al cómic, así como sus características, forman parte de las definiciones que algunos de los autores aportan. Una vez hecho el recorrido histórico del cómic, se observa cómo deviene en un formato más actual, conocido también como novela gráfica. Y dejan ellos esta temática compleja y controversial en lo que toca a este acercamiento entre literatura y medios masivos de comunicación, en lo que lo relevante es cuestionar dónde termina uno y comienza el otro, en qué se sobrelapan y en qué se diferencian.

De Francisco González Gaxiola y Constantino Martínez Fabián "Novela gráfica sin textos. Su posible uso en la enseñanza de la literatura". Este ensayo tiene el objetivo de ubicar la identidad de 
los relatos extensos mediante dibujos sin textos, novela gráfica, para justificar su uso como herramienta formal en la comprensión literaria y como pretexto para la escritura creativa en la escuela media superior. La justificación correspondiente es la falta de referencias válidas para incluir materiales innovadores en los programas escolares. Para ello es relevante la construcción de modelos explicativos al nivel de la teoría literaria, modelos que nos ilustren el cómo y dónde ubicar obras que van más allá de los tradicionales narrativos.

Desde un punto de vista didáctico se exploran tres modelos que explican varias clases de caos: los medios retórico-semióticos, los elementos químicos, y la amplia red de obras y géneros narrativos en función del soporte. De una conclusión tentativa, se pasa, para el análisis de viñetas, a la propuesta de Morelli, enfocada en la revaloración de los detalles en la construcción artística de las ilustraciones y por consiguiente en su respectiva recepción. La propuesta teórico-metodológica se concreta con un acercamiento a la lectura de tres páginas de una novela gráfica, Emigrantes. Con esto se sugiere como recurso las novelas gráficas que, aún sin tener texto, son un excelente medio para encontrar sentido en su respectivo acercamiento a la comprensión del mundo y la sociedad, pues la narrativa puede ser vista como recurso para la enseñanza de la literatura en la que uno participa haciendo y/o en la que uno participa recibiendo. El corolario sostiene que mediante estas prácticas, los estudiantes -si no es mucho presumir- se entretienen, es verdad, pero y más importante, se acercan a la comprensión del sentido de la vida que proporciona la ficción.

González Gaxiola “Gamebooks y narrativa de aventuras”, en el que reflexiona sobre la narrativa (la novela como género emblemático) y los gamebooks. En realidad estamos ante la reflexión sobre un episodio en la evolución de la narrativa, sobre una vertiente ya desaparecida pero que presagiaba el futuro de los videojuegos y la novela electrónica. Su justificación reside en supuestos firmes y en hechos que aún por evidentes tienen que probarse: el trasfondo anecdótico de la novela parece haberse gastado y por ello se han abierto nuevas formas de experimentación. Las formas de entretenimiento que compiten con la novela se han multiplicado. La demanda de novela escrita, lineal, extensa, que responde a incógnitas, va considerablemente a la baja. Nos preguntamos qué posibilidades ofrecen la interacción y el hipertexto a la novela, pues se ve que la concentración en la forma de acercamientos experimentales no ha satisfecho a un público que todavía no comprende ni valora el artificio de la construcción y se agobia ante el desvanecimiento de la línea argumental que buscaba 
otorgar significado en un mundo caótico e irracional. En el presente artículo se pretende encontrar elementos clave, entre la evolución de los gamebooks (narrativa interactiva) y la novela, sus etapas, el surgir de experimentos narrativos impuestos por la hipertextualidad y la interacción en los medios (tecnología de la comunicación y la información). Una posibilidad de impacto didáctico comparativo valoraría el gran número de manifestaciones, resultados que descansan uno en el entretenimiento y el otro en la búsqueda de sentido.

María de los Ángeles Galindo Ruiz de Chávez presenta en "La imagen narrativa hipermodal e hipertextual del cine" un rico acercamiento a la narrativa en el medio fílmico. Cuando una imagen (icono) -o una serie de imágenes-, en su expresión más general, tiene como componente principal lo "narrativo", refiere un suceso ocurrido a alguien, en un tiempo y en un lugar determinado. La imagen narrativa hace referencia a un acontecimiento que es relatado por alguien de manera explícita o implícita, desde un punto de vista específico, con una intencionalidad, representación social e ideologías particulares. Saber leer críticamente la imagen narrativa y todo lo que conlleva el proceso comunicativo en el que se ve imbricada, requiere de acción didáctica mediática. El objetivo de este trabajo es mostrar el diseño de un instrumento de observación para evaluar la literacidad crítica de la imagen narrativa de los alumnos universitarios a través del cine. Para la elaboración del instrumento nos hemos basado en los siguientes teóricos: Paul y Elder (2003a y 2005); Cassany, D. (2006); Marciales (2003), García Madruga, Elosúa, Gutiérrez, Luque y Gárate (1999). El análisis de contenido arroja trece dimensiones en torno a la puesta en práctica del hipertexto y la criticidad a partir del visionado de películas y otros recursos visuales. Los resultados indican también, la necesidad de sistematizar la didáctica de la criticidad en los medios donde la narrativa se hace presente.

María de los Ángeles Galindo, Francisco González Gaxiola y Ana Bertha de la Vara se reúnen para acercarnos a la narrativa en el cine con perspectiva didáctica: "Narrativa de la educación representada en el cine". Si el cine es un reflejo de la realidad simbólica y representa las ideas, costumbres, modas, tendencias ideológicas y concepciones de la vida; resulta de gran interés detenerse a reflexionar, analizar y comprender cómo la educación se ve reflejada en los films en la actualidad. En este sentido, el objetivo de este trabajo es analizar y comprender las historias narradas sobre la educación en el cine. El corpus se compone de cinco películas: Encontrando a Forrester, La sociedad de los poetas muertos, Escritores de la libertad, Con ganas de triunfar y Mentes peligrosas. Se utiliza el análisis de 
contenido como técnica sistemática de descripción de los temas del mensaje en relación a los elementos que intervienen en el proceso educativo, y con ello poder hacer inferencias sobre los conocimientos relativos a las condiciones de producción/recepción de significado en torno al centro educativo, el educando y el educador y sobre las visiones educativas. Los resultados muestran que el contexto de los centros educativos se inserta en una sociedad con serios problemas económicos, sociales, raciales, de violencia y drogas. Los centros educativos buscan responder a la calidad desde la eficacia pero con descuido de la equidad, la relevancia o la eficiencia. La imagen del educador es la del héroe. El educador es protagonista, comprometido, innovador y apasionado con su trabajo. Sin embargo, el contexto le exige al educador adquirir no sólo habilidades profesionales sino socioculturales. El estudiante es representado desde la visión del centro educativo y desde la mirada del educador-proactivo. En el primer caso, si la institución tiene un enfoque burocrático de la educación, el estudiante se concibe a sí mismo como incapaz, pasivo, con baja autoestima, como un objeto sin sentido haciendo como que escucha y como que aprende. En el segundo, el educando es representado como persona, capaz de dar lo mejor de sí mismo, de crecer como ser humano, de aprender significativamente y de desarrollar su pensamiento crítico.

Bárbara Porras Figueroa y Francisco González, con un estudio de perspectiva orientada a los valores e imaginarios sociales: propone en los dibujos animados "Un análisis hermenéutico de La Cenicienta (1950) de Walt Disney desde los estudios de género”. Su artículo aborda un adelanto de investigación de un trabajo más amplio, en el que se pretende hacer una comparación de cuatro largometrajes animados pertenecientes a la franquicia de Princesas Disney, para analizar cómo ha evolucionado la construcción del género en estas representaciones cinematográficas. Las cuatro películas que se analizarán son La Cenicienta (1950), La bella y la bestia (1991), Enredados (2010) y Moana (2016). En este artículo se presenta el análisis del primer largometraje mencionado, para lo cual seguirá la teoría de la Performatividad del Género de Judith Butler: "Asegurar que la identidad de género es performativa implica decir que la misma sólo existe en y a través de un conjunto de actos de género" (Gros, 2016). La metodología a seguir será analizar algunas escenas donde aparecen los personajes principales de la obra, observar las características principales de éstos, con el fin de descubrir estos actos de género que respondían al momento sociohistórico de esa época. 
Finalmente Constantino Martínez Fabián y Berenice Dominguez Hernández analizan varios casos de discursos narrativos de tipo legal: declaraciones preparatorias de inculpados en casos penales mediante un muestreo que involucra delitos de robo y homicidio. El objetivo es determinar qué rasgos lingüísticos caracterizan a estas narraciones que se emplean para juzgar a los individuos sujetos a proceso penal. Nuestra experiencia como peritos en lingüística nos ha permitido detectar patrones sintácticos muy particulares y repetitivos. Si partimos del supuesto vigente en lingüística forense, de que cada individuo posee una huella lingüística única, estos patrones sintácticos difícilmente pueden atribuirse a los inculpados. La hipótesis que guio el trabajo establece que los rasgos lingüísticos repetitivos en las declaraciones pertenecen al Registro Policiaco y que se introducen por el personal que escribe esas declaraciones. Sin embargo, puesto que tales afirmaciones están en primera persona singular (ejemplo: yo afirmo que...), sugiriendo que el inculpado realmente dijo lo que se le atribuye, se violan los derechos lingüísticos de los inculpados y se afecta la impartición de justicia de manera cotidiana. Los resultados indican que los patrones sintácticos y semánticos analizados se introducen por la necesidad de cubrir requisitos legales en las declaraciones.

Dada la evidente falsedad de tales estructuras, se consideran ficciones atribuidas a los inculpados. A fin de demostrar tales ficciones, se analizaron las leyes que regulan el proceso penal y se confrontaron con las declaraciones de los inculpados. Se utilizaron los principios teóricos generados en el área de lingüística forense. Se demuestra que las ficciones pertenecen al registro policiaco y que tales afirmaciones justifican el proceso penal pero no pertenecen a las personas sujetas a proceso legal.

Hemos llegado a la conclusión de que, en lo que hemos presentado, apenas nos acercamos a introducirnos a un campo abierto, polémico por las acotaciones conceptuales que tenemos que enfrentar dada la perspectiva que asumimos. La narrativa supra-género pervasivo se ha inmiscuido en casi todos los géneros que tiene el ser humano para comunicarse en entretenimiento, en reflexión, en experimentación pues las ciencias del espíritu comparten con las ciencias naturales la preferencia por el género narrativo. Se ve casi imposible evadirlo. La situación actual mundial del posmodernismo aporta nuevos y variados géneros que cuestionan principios nodales, vertebrales, incluso ontológicos de lo que se ha denominado narrativo desde las primeras historias que formuló el homo sapiens. ¿Estamos ante el umbral de una nueva realidad con la intromisión de la hipertextualidad, la interactividad y la realidad aumentada? La inmensa galería de textos mixtos, híbridos, de fronteras 
borrosas nos atrae como magneto para investigar y en particular observar, describir, y formular generalidades constitutivas a las que llamamos normas o reglas o leyes explicativas. Se nos ofrece un mundo cambiante muy interesante al que vale la pena atender. 